\title{
Integrating Work Environment Considerations Into Lean and Value Stream Mapping
}

\author{
Edwards, Kasper
}

Publication date:

2017

Document Version

Peer reviewed version

Link back to DTU Orbit

Citation (APA):

Edwards, K. (2017). Integrating Work Environment Considerations Into Lean and Value Stream Mapping.

Abstract from 12th International Conference on Occupational Stress and Health, Minneapolis, Minnesota, United States.

\section{General rights}

Copyright and moral rights for the publications made accessible in the public portal are retained by the authors and/or other copyright owners and it is a condition of accessing publications that users recognise and abide by the legal requirements associated with these rights.

- Users may download and print one copy of any publication from the public portal for the purpose of private study or research.

- You may not further distribute the material or use it for any profit-making activity or commercial gain

- You may freely distribute the URL identifying the publication in the public portal

If you believe that this document breaches copyright please contact us providing details, and we will remove access to the work immediately and investigate your claim 


\title{
INTEGRATING WORK ENVIRONMENT CONSIDERATIONS INTO LEAN AND VALUE STREAM MAPPING
}

\author{
Kasper Edwards, PhD, Technical University of Denmark
}

Public healthcare systems and in particular hospitals in industrialized countries face growing demand in terms of number of patients and new advanced treatments. Funding does not increase proportionately and hospitals are ever searching for methods to increase productivity.

Lean management has emerged a dominant approach to increase productivity in healthcare (Edwards et al. 2012. Radnor, Holweg, \& Waring, 2012). In Denmark lean management has become widely used with hospitals developing their own lean departments and consultants. Lean management is developed in the car manufacturing industry (Spear \& Bowen, 1999; Womack \& Jones, 1996) and is based on standardisation, levelling, and optimisation of work flows through value stream mapping (VSM) (Rother \& Shook, 2009) and eliminating waste.

Lean is essentially a rationalization approach that will reduce waste and increase productivity thereby causing work intensification (Westgaard \& Winkel, 2011) with negative impact on work environment. To compensate for the negative effects of lean a work environment complement (ErgoVSM) has been developed in Sweden (Jarebrandt et al. 2010). EgoVSM integrate work environment considerations into VSM by introducing work environment measurements to be assessed for each identified work activity. The measurements are: 1) Physical: a) work posture, b) weight/force, c) physical load, d) potential, e) porosity and f) variation. And 2) psychosocial dimensions: a) Demands, b) control, c) communication, d) potential, e) mental porosity and f) variation in contents.

However, lean management and the VSM analysis focus on waste to identify workflow problems and develop an improved workflow. The lean mindset and waste analysis is taught to work shop participants by a lean coach.

The focus and mindset of reducing waste is much different from identifying and discussing work environment problems and there might be a tension between the two perspectives. Subsequently it may not be possible to integrate work environment considerations into lean and VSM.

The purpose of this presentation is to examine if it is possible to integrate work environment considerations into lean and VSM. This is done by applying the ErgoVSM method as part of a normal lean intervention. The paper will answer if ErgoVSM can identify physical and psychosocial work environment problems and develop solutions as part of lean and VSM.

Procedures

A collaboration was set up with the lean department of a Danish hospital. ErgoVSM was integrated into a lean project in an Orthopedic bed ward. A lean coach from the lean department was project manager, planned and conducted the lean workshops. Three full day lean workshops were held and ErgoVSM was used as part of the value stream mapping event at the first work shop. Two nurses, two assistant nurses, head nurse and assistant head nurse participated. A researcher (the author) facilitated the ErgoVSM analysis. First, ErgoVSM was explained and one of the activities was analyzed as an example of how to use the scales and fill in results. Second, small groups were formed based on profession who then discussed and evaluated all activities they were part of. Third, results were presented and discussed in plenum work environment problems noted on a white board.

The workshop was audio/video recorded and research notes were taken. The value stream map was photographed and ErgoVSM analysis was collected.

Results

The lean workshop focused on a specific care process: The first 24 hours' post-surgery for hip fracture patients. The process was chosen because patients were not sufficiently mobilized leading to medical complications. This is a work and care intensive period where patients are in pain and often confused from surgery. The care process was mapped with VSM and 24 activities were identified. All activities were assessed with ErgoVSM. Physical work environment problems were identified but countermeasures few were developed. Psychosocial work environment problems were identified but activity specific solutions were not found. Analysis

Participants in the ErgoVSM workshop easily assessed all physical activities. All patient related activities such as mobilization scored very high on physical load. Respondents were surprised by the high physical load but considered this part of their job. This acceptance blocked participants from developing solutions. A participating ergonomist suggested several solutions which were implemented. Psychosocial work environment proved difficult to analyze as this is not solely dependent on a single activity but also context and 
connected activities. However, problems were discussed further and identified as lack of coordination and collaboration. Coordination was approached by implementing a short morning meeting. Collaboration was approached by discussing the need for collaboration and not struggling alone.

Conclusion

Ergonomic value stream mapping (ErgoVSM) can be integrated in to a lean value stream mapping event. ErgoVSM works well when identifying physical work environment issues. However, staff are not trained in developing work environment solutions and will need support for this. Psychosocial work environment is not directly linked to a single activity and ErgoVSM needs further development to be efficient in this area.

CORRESPONDING AUTHOR: Kasper Edwards, PhD, Technical University of Denmark, Building 424, Office 106, 2800 Lyngby, Denmark. 